\title{
Technologie lączności bezprzewodowej w monitorowaniu stanu pojazdu szynowego
}

\begin{abstract}
$W$ artykule omówiono zagadnienia zwiazane $z$ wykorzystaniem technologii łaczności bezprzewodowej w monitorowaniu stanu mobilnego pojazdu szynowego. Przedstawiono standardowq wedtug UIC koncepcje komunikacyjnej sieci pociagowej TCN. Zastosowanie wybranych, bezprzewodowych technologii sieciowych, ze szczególnym uwzględnieniem mobilnych sieci szerokopasmowych omówiono na wybranych przykładach.
\end{abstract}

\section{Wprowadzenie}

W celu zapewnienia bezpieczeństwa ruchu kolejowego, praktycznie konieczne jest ciagłe monitorowanie stanów krytycznych procesów przebiegających w pojeździe i jego otoczeniu. Związane to jest $z$ :

- wyborem mierzonych wielkości oraz z przyjęciem odpowiedniego układu czujników pomiarowych

- wyborem techniki przetwarzania wielkości pomiarowych i metod analizy sygnałów

- przyjęciem wartości granicznych dla krytycznych wielkości

- oceną stanu reprezentowanego uogólnionymi miarami

- przyjęciem odpowiedniej techniki prognozowania

- wyborem odpowiednich metod i procedur decyzyjnych

- opracowaniem modułu prezentacji wyników.

Szczególna złożoność procesu monitorowania stanu pojazdu związana jest z jego mobilnością.

Opracowanie nowych technologii pozwalających na miniaturyzację czujników pomiarowych, zastosowanie cyfrowych układów wbudowanych, wprowadzenie cyfrowych procesorów sygnałowych, zastosowanie technologii telefonii komórkowych, Internetu oraz GPS pozwoliło na zbudowanie bezprzewodowych systemów monitorowania stanu pojazdu oraz jego zespołów funkcjonalnych $[1,3,4,7,13$ i 14$]$.

\section{Bezprzewodowe sieci w monitorowaniu stanu pojazdu szynowego}

Istotnym elementem $\mathrm{w}$ rozwoju metod monitorowania stanu pojazdu szynowego i jego zespołów było zastosowanie elektronicznych metod monitorowania ruchomych środków transportowych ERTMS (European Rail Traffic Management System) [2 i 5] oraz znormalizowanych protokołów komunikacyjnych sieci pociagowej TCN (Train Communication Network) [8].

\subsection{Systemy sygnalizacji i komunikacji w kolejnic-} twie

Europejski System Zarządzania Ruchem Kolejowym ERTMS składa się z:

- Europejskiego Systemu Zarządzania Pociagiem ETCS (European Train Control System)

- systemu transmisji radiowej GSM-R (Global System for Mobile communication for Railway)

- Europejskiej Warstwy Zarządzania Pociągami ETML (European Train Management Layer).

W zależności od rodzaju ruchu na danych liniach oraz istniejącej infrastruktury sygnalizacyjnej, koleje moga wybrać jeden $\mathrm{z}$ trzech poziomów funkcjonowania systemu ETCS. Wspólna dla wszystkich trzech poziomów jest sygnalizacja $\mathrm{w}$ kabinie maszynisty oraz stałe monitorowanie ruchu pociagu.

$\mathrm{Na}$ poziomie pierwszym systemu ETCS stosuje się punktową transmisję informacji do pociagu poprzez przekaźniki bierne. Na tym poziomie system ten stanowi uzupełnienie istniejących, tradycyjnych urządzeń i może być wykorzystywany na liniach o niewielkim lub średnim natężeniu ruchu kolejowego.

Funkcjonowanie systemu ETCS na poziomie drugim opiera się na radiowej łączności GSM-R, wykorzystywanej do wydawania zezwoleń na jazdę, oraz na tradycyjnej technice zajętości toru wykorzystywanej przy przygotowaniu tych zezwoleń.

Funkcjonowanie systemu ETCS na poziomie trzecim polega na wykorzystaniu radiowej łączności GSM-R do wydawania zezwoleń na jazdę i zastapieniu tradycyjnej techniki kontroli zajętości torów przez kombinację punktowej kontroli położenia pociągów za pomocą balis.

System GSM-R zapewnia między innymi usługi:

- transmisji danych cyfrowych

- wywołań grupowych na danym obszarze

- wywołań funkcyjnych

- możliwości łączności z publicznymi sieciami komórkowymi.

System GSM-R działa w paśmie wydzielonym dla kolei $(876 \div 880 \mathrm{MHz}$ oraz $921 \div 925 \mathrm{MHz})$. Dzięki zastosowaniu systemu GSM-R zwiększono bezpieczeństwo ruchu pociągów: diagnostykę pociagu, sterowanie jego ruchem, utrzymanie pożądanej odległości między pociągami oraz ich alarmowe zatrzymanie. 


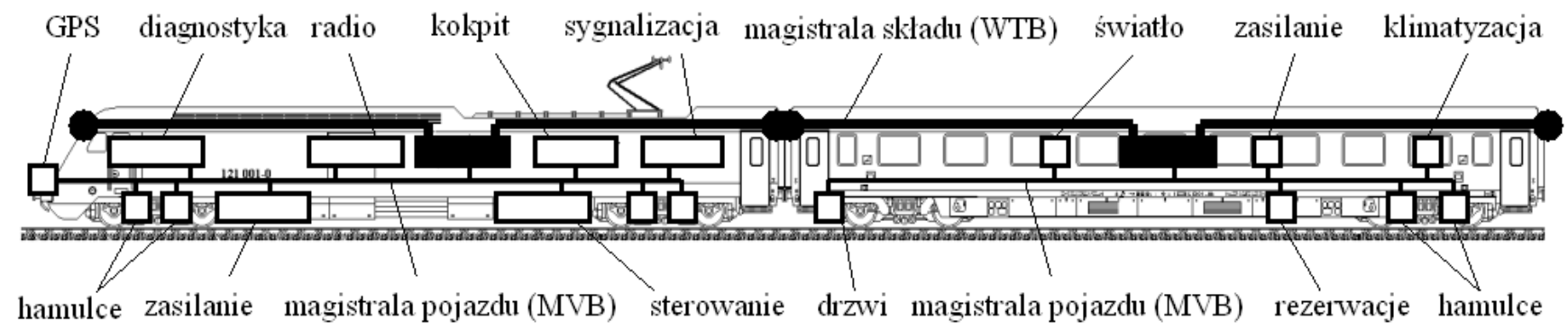

Rys 1. Schemat ideowy sieci pociagowej TCN

Sieć komunikacji pociagowej TCN łączy programowalne wyposażenie pojazdu kolejowego w celu realizacji:

- sterowania pojazdem

- zdalnej diagnostyki i monitoringu

- dostarczania informacji dla pasażerów.

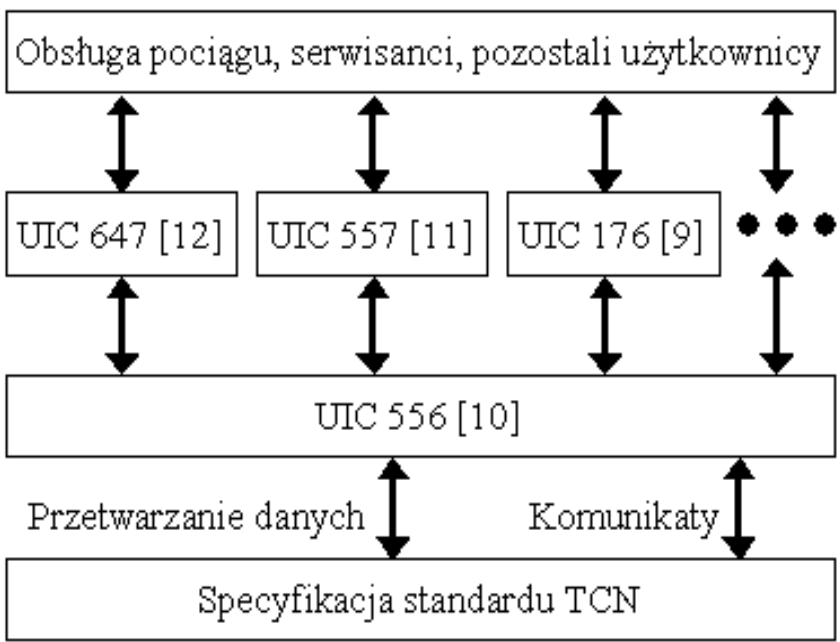

Rys 2. Relacje między warstwą funkcjonalną i warstwą sieciową [10]

W ramach systemu TCN istnieją dwie magistrale: wielofunkcyjna magistrala pojazdu MVB (Multifunction Vehicle Bus), łącząca urządzenia na pojeździe za pomocą skrętki lub światłowodów, oraz przewodowa magistrala składu pociagu WTB (Wire Train Bus), łącząca ze sobą poszczególne pojazdy, co przedstawiono na rys. 1 .

IEEE (Institute of Electrical and Electronics Engineers) Vehicular Society przyjęło TCN jako standard IEEE 1473-1999 type T (norma IEC 61375-1 [8]). Karta UIC 556 [10] jest łącznikiem między funkcjami realizowanymi w pojeździe szynowym, a wytycznymi odnośnie do sieci pociągowej, zawartymi w normie IEC 61375-1, dotyczącej magistrali składu pociagu (rys. 2).
2.2. Przykłady zastosowań technologii sieci przewodowych i bezprzewodowych $w$ monitorowaniu stanu pojazdu szynowego

System TCN zastosowano do połączenia urządzeń różnego typu, znajdujących się na pojeździe szynowym [1]. Zestaw składał się z siedmiu pojazdów dwojakiego rodzaju - pociagu oraz wagonów. Urządzenia na pojeździe tworzyły segment sieci MVB. Każdy segment został podłączony do WTB poprzez ,gateway". Monitoringowi poddano następujące jednostki funkcjonalne (rys. 3):

- sterowanie pociagiem

- zasilanie awaryjne

- kontrola trakcji

- sterowanie hamulcami

- klimatyzacja.

Na rys. 4 przedstawiony został przykładowy system monitoringu elementów jezdnych mechanicznych układów w pojeździe [3], takich jak łożyska, zestawy kołowe, wózki oraz hamulce. W systemie tym zastosowano dwa rodzaje sieci bezprzewodowych, jedną $w$ komunikacji wewnątrz pociagu (intra-train) oraz drugą, wykorzystującą technologię GSM, do przesyłania danych z czujników i danych telemetrycznych składu pojazdu, otrzymywanych z wykorzystaniem urządzenia GPS (Global Positioning System).

Sieć wewnątrzpociagowa typu WLAN (Wireless Local Area Netowrok) wykorzystuje standard IEEE $802.11 \mathrm{~b}$ [3]. Dane z monitoringu poszczególnych czujników przesyłane są siecią do lokomotywy, gdzie po przetworzeniu są prezentowane na monitorze kontrolnym. Aktualizacja tych danych odbywa się co kilka sekund, a ewentualne przekroczenie dopuszczalnych zakresów dla któregoś z monitorowanych parametrów sygnalizowane jest jako stan alarmowy.

Dane otrzymywane z czujników elementów jezdnych pojazdów oraz aktualne położenie składu pociagu są przekazywane poprzez sieć stacji bazowych i łącza dzierżawione w publicznej sieci telekomunikacyjnej PSTN (Public Switched Telephone Network) do serwerów gromadzących i przetwarzających dane. Dane te są następnie udostępniane poprzez serwery internetowe (webserwer) użytkownikom poprzez bezpieczne połączenia SSL (Secure Socket Layer). 


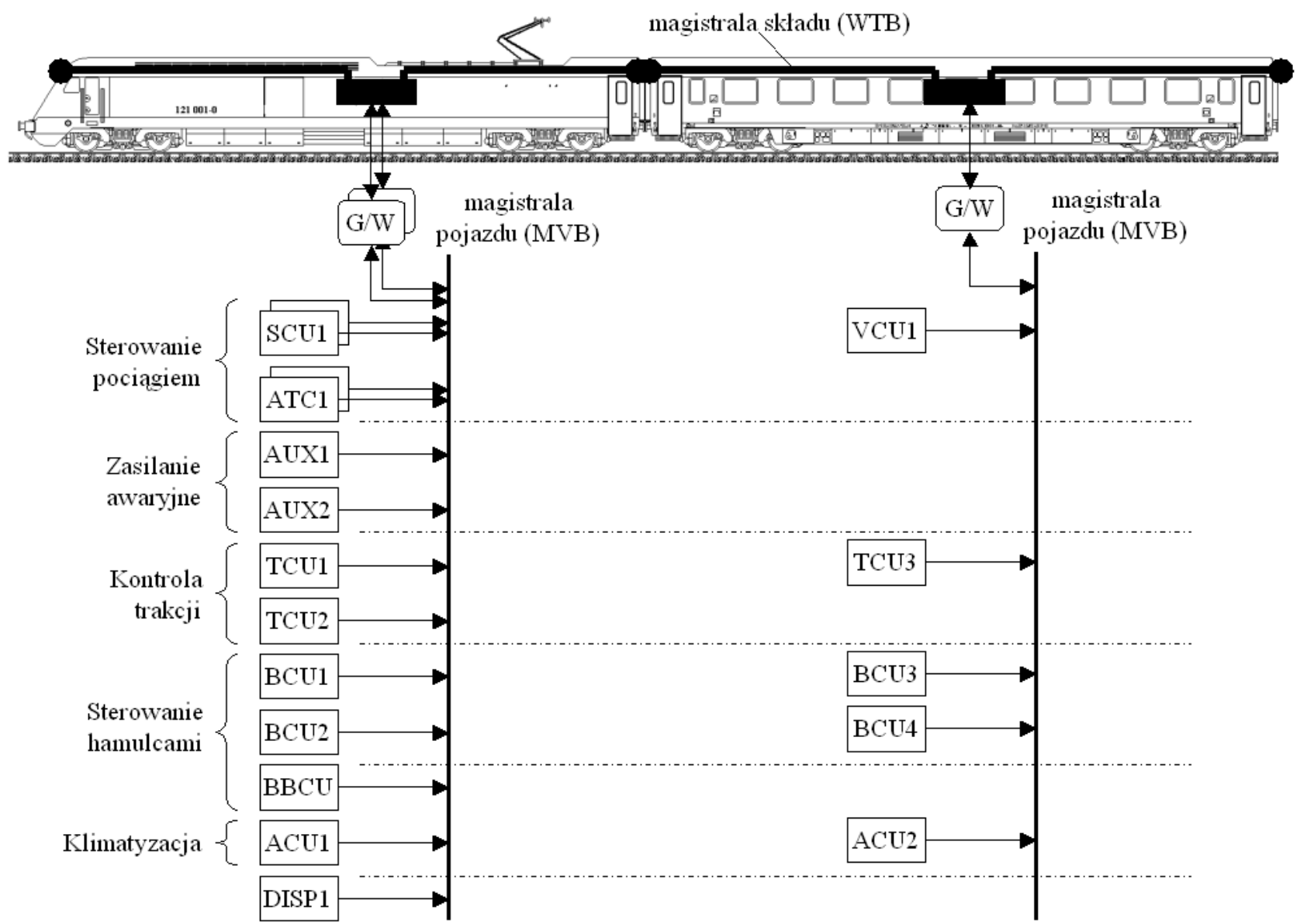

Rys 3. Przykład zastosowania technologii sieci pociagowej (TCN) w monitorowaniu stanu wybranych zespołów funkcjonalnych [1]

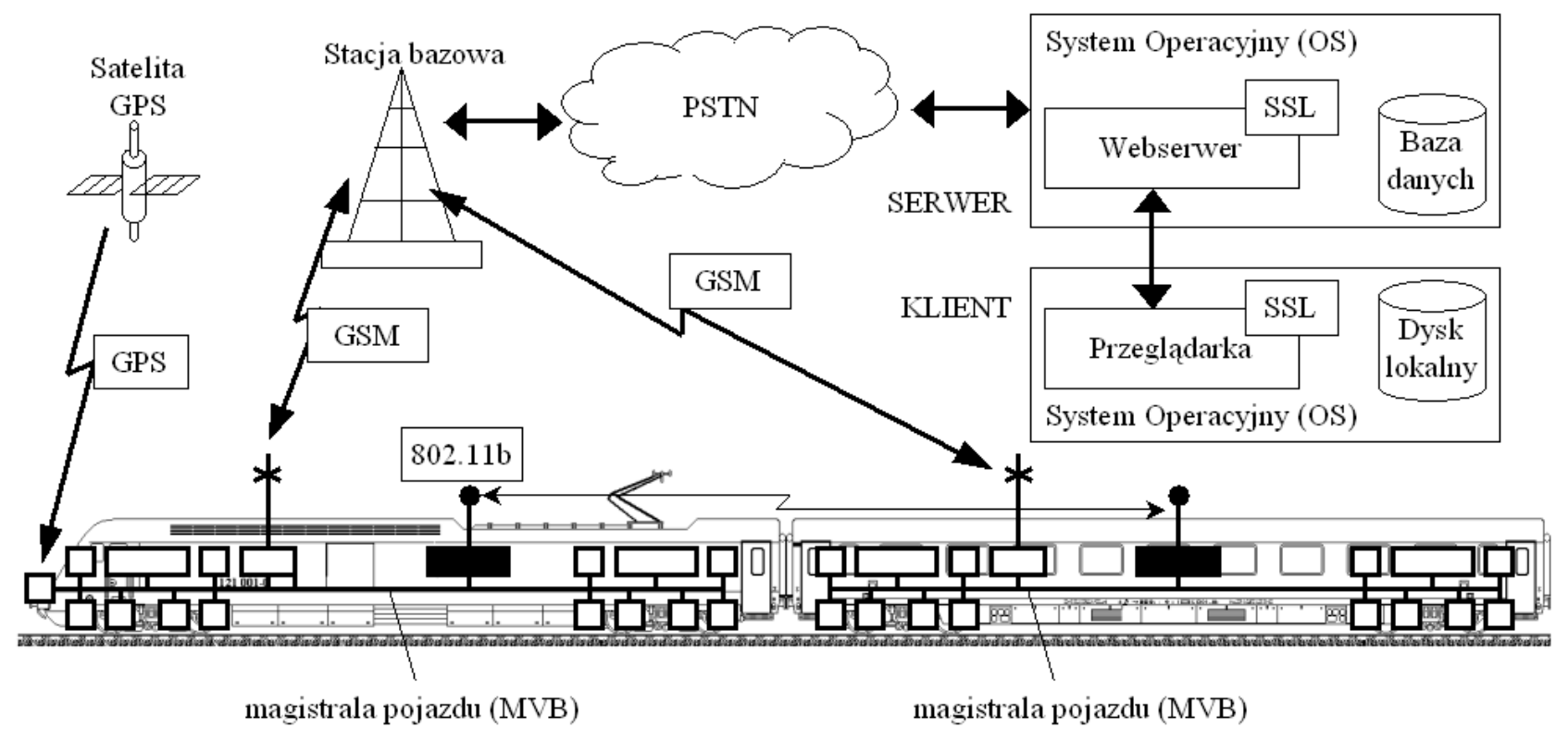

Rys 4. Przykład zastosowania przewodowych i bezprzewodowych technologii sieciowych w monitorowaniu stanu wybranych zespołów funkcjonalnych 
Kolejnym krokiem w rozwoju kolejowych systemów komunikacji [9,10,11 i 12] jest zastosowanie daleko idącej standardyzacji wykorzystywanych technologii (rys. 5). Dotyczy to przede wszystkim:

- sposobu przesyłania i gromadzenia danych w ramach magistrali pojazdu MVB oraz magistrali składu pojazdu WTB

- sposobu przesyłania danych między pociągiem i stacjami bazowymi poprzez zastosowanie mobilnych, szerokopasmowych sieci radiowych oraz technologii ROGATE (Rail Open GATEway) będącej interfejsem pomiędzy magistralą pociagu WTB i technologią radiową GSM-R

- sposobu gromadzenia danych w systemach baz danych $\mathrm{i}$ ich udostępniania $\mathrm{w}$ standardowym formacie XML (Extensible Markup Language)

- sposobu udostępniania informacji przez sieć internetową z wykorzystaniem standardowych protokołów TCP/IP (Transmission Control Protocol/Internet Protocol) oraz HTTP (HyperText Transfer Protocol).

Dzięki standardyzacji technologii przesyłania, przetwarzania i zapamiętywania danych uzyskano między innymi:

- standard dla otwartego systemu współpracującego z urządzeniami sterowania, kontroli i monitoringu, pochodzących od różnych producentów

- zwiększenie stopnia współpracy na poziomie floty pociagów, samego pociągu, pojazdów wchodzących w skład pociągu oraz pomiędzy urządzeniami pomiarowymi i czujnikami

- wzbogacenie usług dostępnych dla podróżnych, w tym system rezerwacji miejsc

- zwiększenie komfortu podróży

- zwiększenie konkurencyjności przewozów kolejowych poprzez zmniejszenie kosztów eksploatacyjnych i zwiększenie efektywności wykorzystania zasobów.
Na rys. 6 przedstawiono koncepcyjny model współdziałania pomiędzy poszczególnymi aktorami w ramach globalnego systemu sieci kolejowej.

Wymiana informacji odbywa się poprzez sieć internetowa, do której podłączone są:

- serwery producentów kolejowych systemów informatycznych, odpowiedzialne za monitorowanie poprawności działania tych systemów i tworzenie dzienników wykonywanych operacji

- serwery nazw domen DNS (Domain Name Service), które zbierają i udostępniają informacje o dostępnych usługach kolejowych systemów informatycznych

- stacje kontroli automatycznej oraz manualnej, pozwalające przewoźnikom na bieżące monitorowanie poszczególnych elementów kolejowej sieci informatycznej

- stacje bazowe, odpowiedzialne za utrzymanie nieprzerwanego połączenia ze wszystkimi składami pociagów poprzez bezprzewodową sieć opartą na technologii GSM-R.

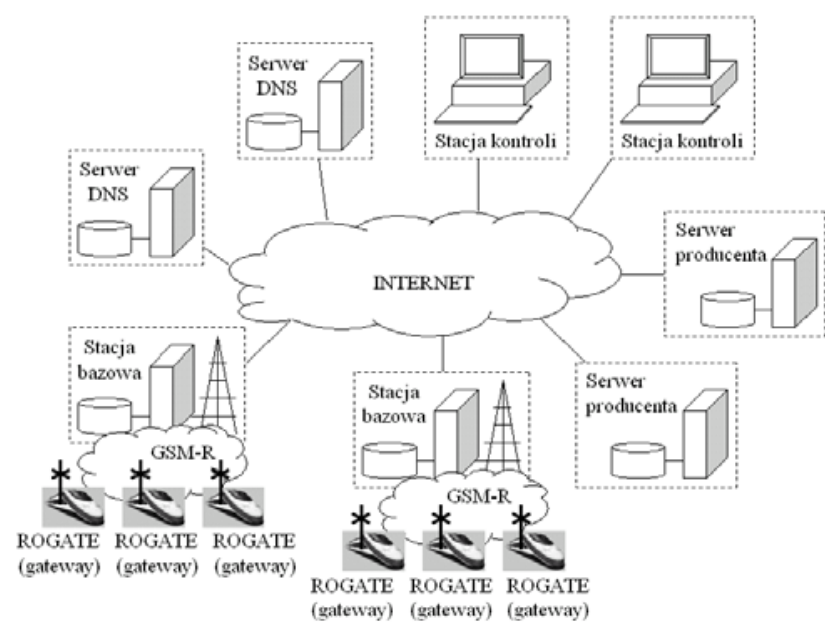

Rys 6. Schemat ideowy współdziałania pomiędzy poszczególnymi aktorami w ramach globalnego systemu sieci kolejowej [13 i 14]

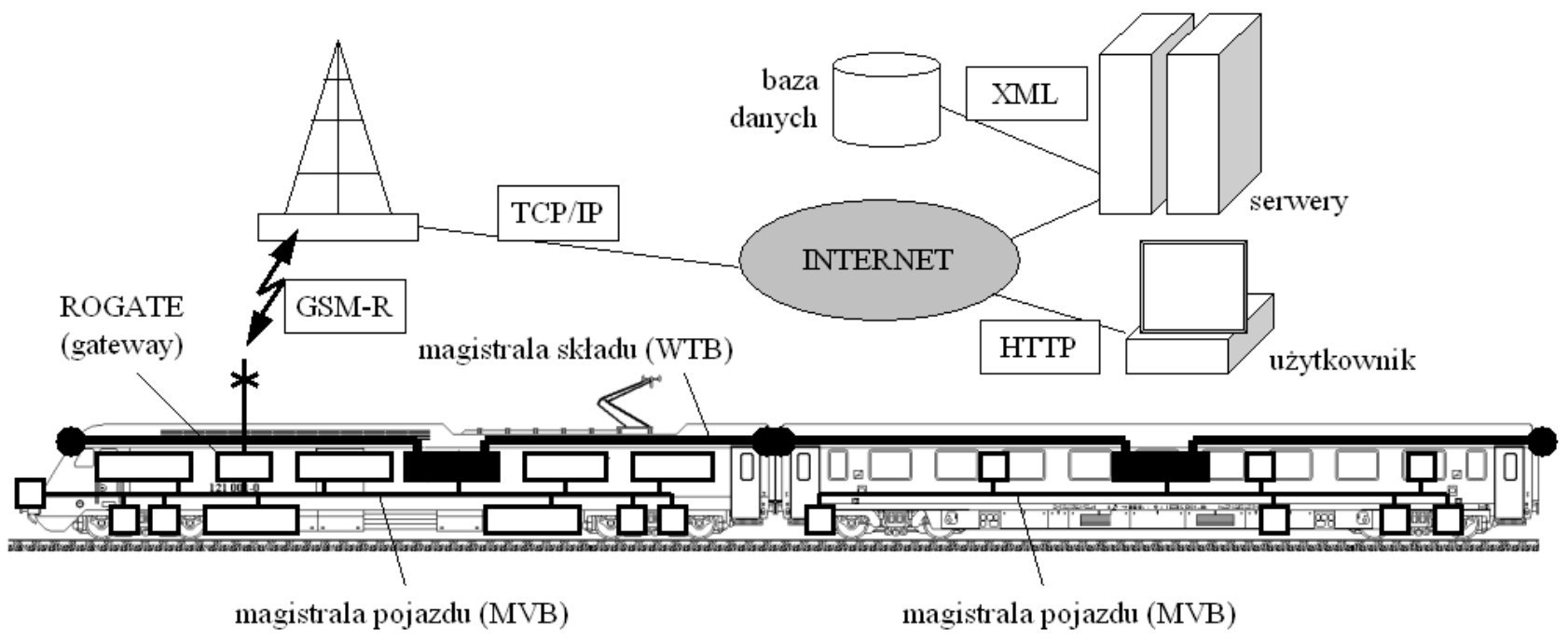

Rys 5. Uogólniony schemat kolejowego systemu informacyjnego 
Stosowane obecnie w sieciach kolejowych technologie GSM-R czy TETRA (TErrestial Trunked RAdio) nie gwarantują uzyskania odpowiedniego dostępu do stacji bazowych przy dużych szybkościach pojazdów. Dlatego opracowane zostały trzy nowe bezprzewodowe technologie specjalnie zaprojektowane dla dostępu mobilnego:

- IEEE 802.11p (Wi-Fi - Wireless Fidelity),

- IEEE 802.16e (WiMAX - Worldwide Interoperability for Microwave Access),

- IEEE 802.20 (MBWA - Mobile Broadband Wireless Access).

W celu oceny przydatności przedstawionych technologii $\mathrm{w}$ aplikacjach mobilnych badaniom poddano pięć charakterystyk: sprawność, zasięg, niezawodność, bezpieczeństwo oraz mobilność [7].

Sprawność określono na bazie przydzielonego pasma oraz występującego opóźnienia. W sieciach wąskopasmowych można skutecznie przesłać pliki tekstowe, a w sieciach szerokopasmowych można przesyłać pliki multimedialne. Dla usług realizowanych $\mathrm{w}$ czasie rzeczywistym (np. głos) występujące opóźnienie jest charakterystyką krytyczną.

Zasięg determinuje: odległości między stacjami bazowymi, liczbę urządzeń wspierających infrastrukturę oraz mechanizm przenoszenia połączeń między sąsiednimi stacjami bazowymi. Istnieją dwie metody przenoszenia połączeń: twarde i miękkie.

Miękkie przenoszenie stosowane jest w sieciach komórkowych takich jak GSM oraz CDMA. Polega ono na ustanowieniu nowego połączenia pomiędzy mobilnym obiektem a kolejną stacją bazową zanim zostanie przerwane aktualnie istniejące połączenie $\mathrm{z}$ najbliższą stacją bazową. W przypadku twardego przenoszenia połączeń, mobilny obiekt $\mathrm{w}$ danym momencie utrzymuje połączenie tylko $\mathrm{z}$ jedną stacją bazowa. Pod względem wykorzystania zasobów sieci twarde przenoszenie połączeń pozwala na sprawniejsze wykorzystanie dostępnego pasma, co skutkuje jednak zwiększeniem opóźnienia w przesyłanych danych.

Niezawodność mierzona jest średnią liczbą utraconych pakietów oraz średnią liczbą utraconych połączeń, co spowodowane jest między innymi poprzez środowisko (pogoda, przeszkody, itp.) Niezawodność determinuje w sposób istotny funkcjonowanie sieci.

Bezpieczeństwo oceniane jest na podstawie poziomu i jakości zabezpieczeń w postaci kodowania i uwierzytelnienia. Zdecydowana większość działań w sieci wymaga wysokiego poziomu bezpieczeństwa.

Mobilność jest definiowana prędkością maksymalną mobilnego obiektu, przy której technologia zapewnia zdefiniowaną jakość połączeń.

Zestawienie wyników oceny przeprowadzonej analizy porównawczej dla obecnie stosowanych technologii sieciowych przedstawiono $\mathrm{w}$ tabeli 1 [7].
Porównanie podstawowych własności bezprzewodowych technologii wąskopasmowych

\begin{tabular}{|l|l|l|l|}
\multicolumn{3}{c}{ pasmowych } & \multicolumn{1}{c|}{ Tabela 1 } \\
\hline & GSM-R & TETRA & $\begin{array}{l}\text { GT800 } \\
(\mathrm{G} 3)\end{array}$ \\
\hline $\begin{array}{l}\text { Przepusto- } \\
\text { wość [kb/s] }\end{array}$ & $2,4 \div 28,8$ & $96 \div 384$ & $\begin{array}{l}2000, \\
<144^{*}\end{array}$ \\
\hline $\begin{array}{l}\text { Opóźnienie } \\
{[\text { ms }]}\end{array}$ & $\begin{array}{l}\text { około } \\
1000\end{array}$ & $\begin{array}{l}\text { około } \\
500\end{array}$ & około 250 \\
\hline Zasięg [km] & $5 \div 10$ & $10 \div 15$ & $2 \div 5$ \\
\hline $\begin{array}{l}\text { Spektrum } \\
{[\mathrm{MHz}]}\end{array}$ & $\begin{array}{l}876 \div 880 \\
921 \div 925\end{array}$ & $\begin{array}{l}806 \div 821 \\
851 \div 866\end{array}$ & $\begin{array}{l}\text { poniżej } \\
2700\end{array}$ \\
\hline
\end{tabular}

*przy prędkościach pojazdu powyżej $250 \mathrm{~km} / \mathrm{h}$

Zestawienie wyników oceny przeprowadzonej analizy porównawczej dla przyszłościowych, szerokopasmowych technologii sieciowych przedstawiono $\mathrm{w}$ tabeli 2 [7].

Porównanie podstawowych własności bezprzewodowych technologii szerokopasmowych

Tabela 2

\begin{tabular}{|l|l|l|l|}
\hline & $\begin{array}{l}\text { Wi-Fi } \\
802.11 \mathrm{p}\end{array}$ & $\begin{array}{l}\text { WiMAX } \\
802.16 \mathrm{e}\end{array}$ & $\begin{array}{l}\text { MBWA } \\
802.20\end{array}$ \\
\hline $\begin{array}{l}\text { Przepusto- } \\
\text { wość [Mb/s] }\end{array}$ & 54 & 100 & 16 \\
\hline $\begin{array}{l}\text { Opóźnienie } \\
{[\mathrm{ms}]}\end{array}$ & 50 & $25 \div 40$ & $10 \div 30$ \\
\hline Zasięg [km] & 0,3 & $\begin{array}{l}50 * \\
8 * *\end{array}$ & $\begin{array}{l}1 \div 10 \\
(\max 15)\end{array}$ \\
\hline $\begin{array}{l}\text { Spektrum } \\
{[\mathrm{MHz}]}\end{array}$ & 5900 & $\begin{array}{l}2000^{*} \\
6000^{* *}\end{array}$ & $\begin{array}{l}1250 \quad 1 \mathrm{ub} \\
5000\end{array}$ \\
\hline
\end{tabular}

* przy widocznej antenie

** przy niewidocznej antenie

Najbardziej przyszłościowym rozwiązaniem w mobilnych aplikacjach jest technologia IEEE 802.16e (WiMAX). Technologia ta umożliwia obsługę urządzeń stacjonarnych bez konieczności zapewnienia warunków bezpośredniej widoczności anten, urządzeń przenośnych oraz ruchomych, poruszających się z prędkością do $120 \mathrm{~km} / \mathrm{h}$.

System mobilny WiMAX jest systemem szerokopasmowym, który zapewnia stacjonarny i mobilny dostęp do sieci szerokopasmowej [6]. Podstawowym trybem wielodostępu, zastosowanym w systemie mobilnym WiMAX, jest oparta na transmisji wielotonowej metoda OFDMA (Orthogonal FrequencyDivision Multiple Access), w której podnośne OFDM są dynamicznie przydzielane różnych użytkownikom. Dzięki zastosowaniu tej metody wielodostępu i modulacji, system zapewnia transmisję bez widoczności 
anten nadawczo-odbiorczych w środowisku radiowym, charakteryzującym się wielodrogowością i związanymi z nią zanikami sygnału. W zależności od konkretnego środowiska i dostępnego pasma szerokość pasma transmitowanego sygnału może przyjmować różne wartości i z tego względu elastyczne podejście do rozwiązania tego problemu doprowadziło do modyfikacji metody OFDMA, zwanej skalowalnym wielodostępem S-OFDMA. Umożliwia ona zastosowanie szerokości kanałów od 1,25 $\mathrm{MHz}$ do $20 \mathrm{MHz}$. Liczba możliwych parametrów systemu i ich kombinacji jest bardzo duża, co mogłoby utrudniać konfigurację systemu. Wobec tego wprowadzono tzw. system profili WiMAX, w którym profil określa zarówno podstawowy, obowiązkowy zbiór parametrów, które musi spełniać urządzenie działające w określonej sieci, jak i jego parametry opcjonalne. Pierwszy opublikowany zbiór profili będzie dotyczył kanałów o szerokości pasma $5 \mathrm{MHz}, 7 \mathrm{MHz}, 8,75 \mathrm{MHz}$ oraz $10 \mathrm{MHz}$, które będą funkcjonować w licencjonowanych pasmach w zakresach 2,3 GHz, 2,5 GHz oraz 3,5 $\mathrm{GHz}$.

System mobilnego dostępu do sieci szerokopasmowej WiMAX charakteryzuje się dużymi szybkościami transmisji danych dzięki zastosowaniu:

- nowoczesnych technik warstwy fizycznej, takich jak technika antenowa MIMO (Multiple-Input and Multiple-Output)

- elastycznych schematów przydziału kanałów

- zaawansowanych metod kodowania i modulacji.

Przewiduje się osiagnięcie maksymalnej szybkości transmisji w pojedynczym sektorze, przy wykorzystaniu kanału o szerokości $10 \mathrm{MHz}$, w łączu w dół na poziomie $63 \mathrm{Mb} / \mathrm{s}$, a w łączu w górę na poziomie 28 $\mathrm{MB} / \mathrm{s}$.

System WiMAX zapewnia wysoką jakość obsługi QoS (Quality of Service) dzięki zdefiniowaniu odpowiednich strumieni obsługi i zastosowaniu protokołu IP. Wprowadzono również dodatkowe narzędzia w postaci podziału strumienia transmisji na podkanały $i$ sterowania na podstawie protokołu MAP (Media Access Protocol), dzięki czemu można w kolejnych ramkach elastycznie rozdzielać dostępne zasoby w dziedzinie czasu, częstotliwości i przestrzeni.

Duża skalowalność umożliwia dostęp do pasm elektromagnetycznych EM o różnych szerokościach w różnych rejonach świata i pozwala na wykorzystanie systemu WiMAX do realizacji różnorodnych zadań, np. szerokopasmowego dostępu do Internetu w miejscach, gdzie działanie ADSL nie jest możliwe, połączenia sieci rdzeniowej z oddalonymi centrami działania sieci Wi-Fi (hotspot), wzbogacenia dostępu szerokopasmowego do Internetu w środowiskach miejskim i podmiejskim.

Wysokie bezpieczeństwo sieci WiMAX jest konsekwencją stosowania kart SIM, kart inteligentnych, certyfikatów cyfrowych, nazw użytkowników i ich haseł.
Dzięki możliwości przejmowania połączenia z czasem trwania procedury nie przekraczającym $50 \mathrm{~ms}$, i równoczesnym zapewnieniu bezpieczeństwa transmisji, system WiMAX charakteryzuje się dużą mobilnością. Przykładową strukturę sieci wykorzystującą szerokopasmowe sieci bezprzewodowe, w tym IEEE 802.16e, przedstawiono na rys. 7 [7].

W ramach przedstawionej struktury wydzielone zostały trzy podsieci: sieć intranetowa w ramach składu pociagu, sieć łącząca pociagi ze stacjami bazowymi oraz szerokopasmowa sieć infrastruktury kolejowej.

Intranetowa sieć składu pociagu zbudowana jest na bazie dwóch rodzajów sieci Wi-Fi.

Sieć oparta na technologii IEEE 802.11b (lub na kolejnej jej generacji 802.11g), działająca na częstotliwości $2,4 \mathrm{GHz}$ i przepustowości do $54 \mathrm{Mb} / \mathrm{s}$, łączy ze sobą czujniki i stanowiska pomiarowe STA, zainstalowane w każdym z pojazdów, z punktami dostępowymi AP (Access Point) w ramach bezprzewodowej sieci pojazdu WVN (Wireless Vehicle Network).

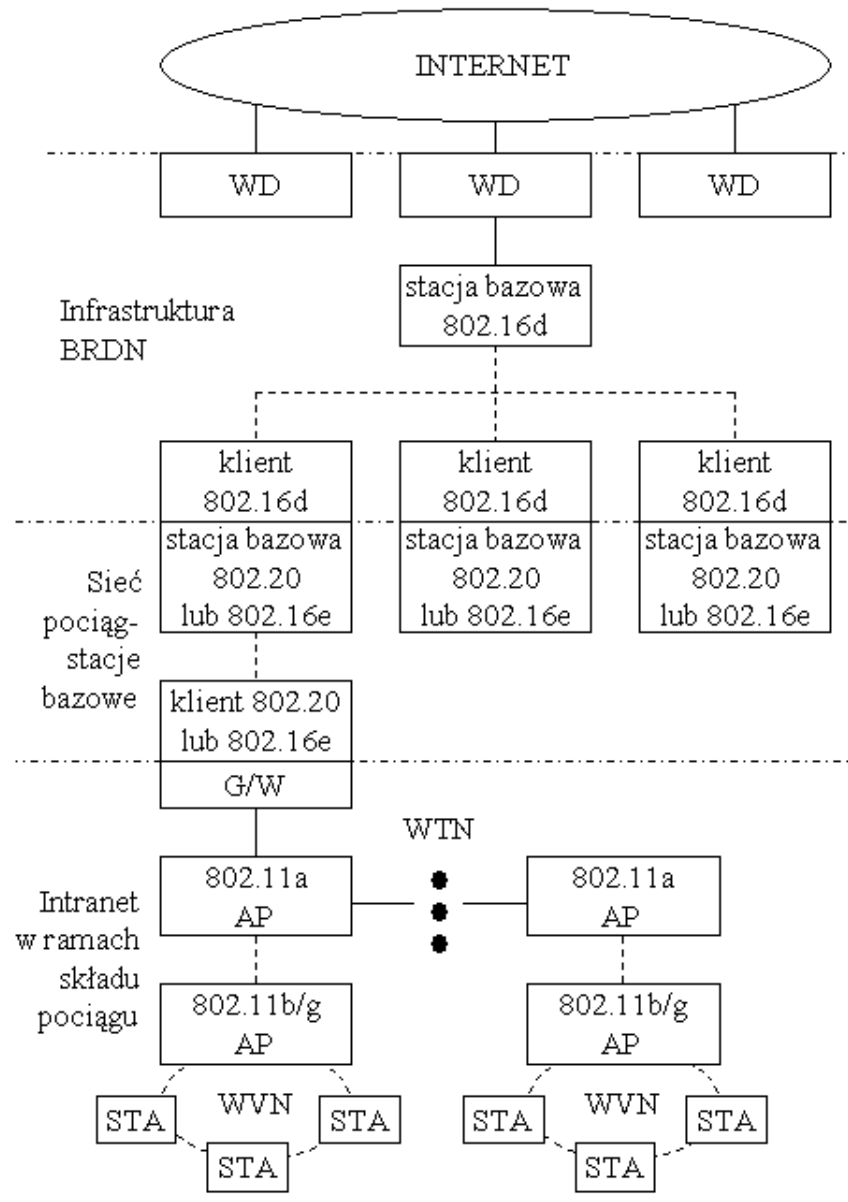

Rys 7. Przykład zastosowania szerokopasmowych, bezprzewodowych technologii sieciowych w monitorowaniu stanu wybranych zespołów funkcjonalnych

Sieć oparta na technologii IEEE 802.11a, działająca na częstotliwości $5 \mathrm{GHz}$ i przepustowości do 300 $\mathrm{Mb} / \mathrm{s}$, łączy ze sobą poszczególne pojazdy, tworząc bezprzewodową sieć składu pojazdu WTN (Wireless Train Network). Zastosowanie standardu IEEE 
802.11a pozwoliło na wyeliminowanie ewentualnych interferencji między sieciami pojazdów, a siecią składu pociagu (różne częstotliwości pracy). Ponadto, sieć IEEE 802.11a posiada kilkukrotnie większą przepustowość, co pozwala na wymianę znacznej ilości danych między poszczególnymi pojazdami składu pociagu.

W lokomotywie zainstalowany został gateway G/W, który odpowiedzialny jest za połączenie sieci intranetowej pociagu $\mathrm{z}$ siecią stacji bazowych $\mathrm{w}$ standardzie IEEE 802.16e (WiMAX) lub IEEE 802.20 (MBWA). Sieć pociag-stacje bazowe jest siecią mobilną, tzn. połączenia realizowane między lokomotywą a stacjami bazowymi nie są tracone $\mathrm{w}$ momencie przemieszczenia się składu pociagu do kolejnej stacji bazowej. Wszystkie stacje bazowe znajdujące się w przedstawionej strukturze sieci są połączone w ramach szerokopasmowej, cyfrowej sieci kolejowej BRDN (Broadband Railway Digital Network), opartej na standardzie IEEE 802.16d. Sieć ta podłączona jest do Internetu poprzez węzły dostępowe WD, co pozwala na przesyłanie danych zbieranych przez czujniki i układy pomiarowe, zainstalowane na pojazdach, do serwerów, gdzie następuje ich przetwarzanie.

\section{Podsumowanie}

Przedstawione zagadnienia dotyczą aktualnych, a także perspektywicznych rozwiązań $\mathrm{w}$ dziedzinie zastosowania technologii łączności przewodowej i bezprzewodowej dla zapewnienia bezpieczeństwa ruchu kolejowego. Omówiono systemy sygnalizacji i komunikacji w kolejnictwie, zwracając szczególną uwage na wykorzystanie międzynarodowych standardów, w tym opracowane przez organizacje kolejowe (UIC).

Podkreślono istotność wdrożenia sieci pociągowej TCN dla zapewnienia bezpieczeństwa ruchu. Wskazano na ogromne możliwości rozwojowe bezprzewodowych, mobilnych technologii komunikacyjnych w zakresie monitorowania stanu pojazdu szynowego i jego zespołów funkcjonalnych.

\section{Literatura}

[1] Cho Ch.-H., Lee J.-D., Lee J.-H., Kim K.-H., Kim Y.-J.: Design of the Train Network Simulator Base on Train Communication Network, ISIE, Pussan, 2001.

[2] Dabrowa-Bajon M.: Podstawy sterowania ruchem kolejowym, WPW, 2002.

[3] Donelson J.: Performance of an On-Board Monitoring System in a Revenue Service Demonstration, Proceedings of JRC2005.

[4] Nieva T., Fabri A., Wegmann A.: Remote Monitoring of Railway Equipment Using Internet Technologies, Technical Report No. DSC/2001/18, 2001.

[5] Szulc W.: Zastosowanie standardu GSM-R w systemach zarzqdzania ruchem kolejowym, Zabezpieczenia, Nr 5, 2006.

[6] Wesolowski K., Wódczak M.: System mobilnego szerokopasmowego dostęu radiowego WiMAX IEEE 802.16e, Przeglad Telekomunikacyjny, No. 6, 2006.

[7] Zou F., Jiang X., Lin Z.: Implementing Wireless Broadband Digital Network for the Railway Information System, Proceedings of JRC2006.

[8] IEC 61375-1, Electric railway equipment - Train bus - Part 1: Train Communication Network, 1999.

[9] Karta UIC 176. Wymagania dla elektronicznych tablic informujacych podróżnych $w$ pociagach. Wyd. 1 z czerwca 2001.

[10] Karta UIC 556. Przekazywanie informacji $w$ pociagu. Wyd. 4 z sierpnia 2005.

[11] Karta UIC 557. Technika diagnostyki w wagonach pasażerskich. Wyd. 2 ze stycznia 1998.

[12] Karta UIC 647. Model funkcjonalny zdalnego sterowania z pojazdów napędzanych. Wyd. 1 z maja 2006.

[13] Projekt TrainCom: www.traincom.org.

[14] Projekt ROSIN: www.labs.it/rosin. 